\title{
Using syndromic surveillance to monitor response to cyanotoxin contamination event
}

\section{Kelly E. Cogswell}

Acute and Communicable Disease Prevention, Oregon Health Authority, Portland, Oregon, United States

Objective

Examine healthcare seeking behavior in a population exposed to low levels of cyanotoxins in the public drinking water supply and quantify how publicity of the event may have affected perceptions of risk in the affected population.

\section{Introduction}

Cyanotoxins are unregulated, emerging contaminants that have been associated with adverse health effects, including gastroenteritis, when consumed at high levels [1,2]. In May and June of 2018 cyanotoxins were detected in the public drinking water system for Salem, OR at levels above Environmental Protection Agency (EPA) health advisory levels for sensitive groups [3]. Sensitive groups were defined as children under 6 , elderly adults, pregnant women, nursing mothers, people with compromised immune systems, people receiving dialysis, people with pre-existing liver conditions, and pets. Several health advisories were issued, and there was substantial media coverage of the event. The Oregon Health Authority (OHA) organized an Incident Management Team (IMT), which coordinated activities with other state and local agencies. Oregon ESSENCE staff used syndromic surveillance to monitor the population for health effects and healthcare seeking behavior.

\section{Methods}

Oregon ESSENCE staff developed syndromic surveillance queries to monitor visits made to local emergency departments (i.e., visits by hospital location), as well as visits made by residents of the affected area (i.e., visits by patient location). Specifically, Oregon ESSENCE staff monitored total visits, gastroenteritis syndrome, visits by age group, and mentions of the word 'water' daily during the relevant time period. OHA communications staff tracked media coverage of the event. After the event, Oregon ESSENCE staff reconciled syndromic surveillance visit data with water test data, health advisory status, and media coverage to characterize how messaging may have affected healthcare seeking behavior.

\section{Results}

Cyanotoxins were detected at levels above EPA guidelines for sensitive groups on 9 days between May 23, 2018 and June 19, 2019. OHA identified 67 news articles related to the event published in May and 179 published in June. Additionally, there was an unquantified amount of activity on social media, and a mass text alert that was sent out by the Oregon Office of Emergency Management. Visits for gastroenteritis were highest on the days immediately following the issuance of the first drinking water advisory. The first drinking water advisory was issued three days after the first results that contained cyanotoxins at levels exceeding the EPA guidelines for sensitive groups were received. Visits where the word 'water' was mentioned were similarly elevated immediately after the first drinking water advisory was issued. However, visits for gastroenteritis were also above expected levels on one day that had a water sample above EPA guidelines for sensitive groups, but before the first drinking water advisory was issued.

\section{Conclusions}

Because cyanotoxins are unregulated, limited federal guidance was available and it took several days for the Oregon Health Authority to develop state guidance and educational materials. This delay contributed to public confusion about the level of risk associated with drinking the water, as well as confusion about which groups of people should avoid drinking the water. Our data suggest that emergency department visit behavior was largely driven by publicity of the event.

Visits to the emergency department for gastroenteritis and mentions of the word 'water' decreased as more public information and guidance became available. However, we cannot rule out a real health effect related to cyanotoxins in the drinking water for area residents. One lesson learned from this type of high profile event relates to tracking of media coverage; it is difficult to measure how many people media coverage actually reaches, and attempting to characterize media coverage becomes more difficult after the event. 
ISDS 2019 Conference Abstracts

\section{References}

1. U.S. EPA (United States Environmental Protection Agency). 2015. Drinking Water Health Advisory for the Cyanobacterial Toxin Cylindrospermopsin. EPA 820R15101, Washington, DC; June, 2015. Available from: http://water.epa.gov/drink/standards/hascience.cfm

2. U.S. EPA (United States Environmental Protection Agency). 2015. Drinking Water Health Advisory for the Cyanobacterial Toxin Microcystin. EPA 820R15100, Washington, DC; June, 2015. Available from: http://water.epa.gov/drink/standards/hascience.cfm

3. U.S. EPA (United States Environmental Protection Agency). 2015. 2015 Drinking Water Health Advisories for Two Cyanobacterial Toxins. EPA 820F15003, Washington, DC; June, 2015. Available from: https://www.epa.gov/sites/production/files/2017-06/documents/cyanotoxins-fact_sheet-2015.pdf 